but was surprised to find the high incidence of quite severe mental illness. This was partly determined by my choice of subject for the morning. There were some major problems in which I was probably quite helpful, e.g. people ringing up about relatives who were clearly very psychotic but who had contacted me rather than any statutory authorities. I was able to give advice. Indeed, almost all the advice given concerned how to get through the health system, e.g. how to get referred to mental health services by GPs.

In addition to being the expert on the show, I have been telephoned on a number of occasions to speak about psychiatric aspects of events in the news. Hopefully, this also has helped portray a better light on mental health problems than there would have been if I had not spoken.

The aim of being the Radio York Psychiatrist was purely to increase public awareness of mental health problems and try to show them in a more positive light. It is hard to ascertain whether this has been successful. However, it does appear that those who have telephoned me on the 'phonein have been suffering from real mental distress and have been able to be directed to appropriate services.

\section{References}

Cardno, A. G. S. \& Simpson, C. J. (1991) The first nine months of a community mental health team: a study of communication and attitude. Psychiatric Bulletin, 15, 133-135.

Clare, A. W. (1990) Psychiatry in the Media - 11 th Curran Memorial Lecture presented on 10 May 1989 at St George's Hospital Medical School, London.

SIMPSON,C.J. (1989)All patients great and small. Psychiatric Bulletin, 13, 605-606.

TALBOT, J. A. (1985) Our patients' future in a changing world: the imperative for psychiatric involvement in public policy. American Journal of Psychiatry, 142, 1003-1008.

Psychiatric Bulletin (1991), 15, 462-463

\title{
Video news
}

\section{The problem drinker}

Making a good video is difficult enough: knowing who you are making it for sometimes gets lost in the process. So it is with the two tapes currently reviewed: Alcohol-The Interviews and New Approaches to the Problem Drinker. On the one hand the content and production is good, but on the other hand the intended application is less certain. In practice it is likely that the two tapes will be used as stand-alone programmes suiting the non-specialist, and in particular the medical non-specialist.

The first tape is a scene setter and for most practitioners could safely be omitted. The contributors discuss aspects of epidemiology and alcohol-related social, psychological, and physical problems. Rather than giving a preferred approach to addiction problems, there is an effort to balance the merits of Jellinek and his typology against the newer idea of a dependence syndrome. I suspect that this was a compromise by the contributors, but it is an example of how the message is muddied. A similar problem cropped up with the physical illness section; a very nicely presented section covers familiar ground for doctors, but lacks the explanation that would make it of interest to non-medics.

The second, and longer tape is presented as a process of intervention in three steps: first engaging the patients, second detoxification, and third on changing drinking habits. There is a quality of clinical advice which can only come from practitioners actively involved in the business of patient care. The first section was particularly strong on reminding viewers of some very basic techniques, such as being courteous: "I am awfully glad you came this morning - can I hang your coat up", is not heard ringing through out-patient departments as much as might be desired. As the programme moves onto more specialist treatments and prevention, then so it becomes more a resume of the kind of things that might usefully be done. One or two scenes are repeated from the first tape which is slightly irritating.

In summary, these are good tapes but their purpose is ambiguous. Their strength comes from the contributors' ability to present specialist skills without specialist trappings. Overall the programmes come across as awareness raising rather more than skills teaching. This inconsistency of purpose is perhaps the weakness.

DunCan Raistrick

\section{Videocopying of the Institute of Neurology Cinefilm Library}

The Institute of Neurology Cinefilm Library, comprising 97 mostly short, silent, monochrome and 
colour studies of individual case-histories from the National Hospital for Nervous Diseases selected and compiled by Professor John Marshall, former Professor of Clinical Neurology in the University of London, constitute an outstanding visual record of the clinical features of nervous disease. Hitherto, this valuable resource existed only as a collection of unedited $16 \mathrm{~mm}$ films, many of them in poor condition, and could be viewed only by special arrangement at the Institute of Neurology, Queen Square, London WCl. However, thanks to a grant made by the History of Medicine Panel of the Wellcome Trust in January 1989, these films have now been re-edited and videocopied, and thus made potentially available to a much wider professional public.

The videocopied Cinefilm Library includes 94 films grouped according to their clinical subjectmatter onto 14 videotapes which vary from 20 to 80 minutes in length. Each video comprises one or two major clinical subject groupings, including apraxia, chorea, epilepsy, hysteria, and involuntary movements. In addition there is a videotape of various diseases including Gilles de la Tourette syndrome, Friedreich's Ataxia, Myxoedema, Wilson's disease and Creutzfeld-Jacob disease. Full descriptions of each videotape are given in a catalogue prepared by the Institute of Neurology, copies of which are available on request from the Wellcome Trust. Members of the medical and academic professions engaged in teaching, research and/or practice in clinical neurosciences may view any part or parts of the Library by appointment at the Institute of Neurology and from March 1992, at the Centre for Medical Science and
History. VHS copies may also soon be available to members of the medical and academic professions on a restricted basis.

\section{Tape details}

Ratings
*** highly recommended
** recommended
* worth looking at
Alcoholism - The Interviews: and New Approaches to the Treatment of Alcoholism

Production: Turnip Video/Professor G. Edwards et al

Distributor: Turnip Video, 193 Queen's Road, Wimbledon, London SW19 8NX

Details: Video; 28 and 42 mins; 1989.

Rating/audience: ${ }^{*}, M, U G$ and $P G$

Institute of Neurology Cinefilm Library

Production/ Institute of Neurology, Queen

viewing: $\quad$ Square, London WCIN 3BG

Maida Vale Hospital, 4 Maida

Vale, London W9 1TL

The Wellcome Trust, 1 Park

Square West, London NW1 4LJ

Centre for Medical Science and

History, 183 Euston Road, London NW1 2BP

Details: $\quad$ VHS Tapes $\times 14 ; 20-80 \mathrm{mins}$

Rating/audience: **, P, PG

\section{Miscellany}

\section{New publications}

The Law Commission's consultation paper Mentally Incapacitated Adults and Decision-making: an Overview is obtainable free of charge from the Law Commission, Conquest House, 37-38 John Street, Theobalds Road, London WCIN 2BQ to anyone who wishes to send a formal response to it before 31 July 1991. Otherwise it can be purchased from HMSO, price $£ 6.90$.

At Home in the Community is a directory of housing and support services for people in long term contact with mental health agencies compiled by Jan Sherlock, price $\mathbf{6 6 . 9 5}$. It is obtainable from Good
Practices in Mental Health, 380 Harrow Road, London W9 2HU (telephone 071289 2034).

A booklet outlining the York Monitoring System software package is now available for purchase. It is designed to help district health authorities implement a 'Care Programme' approach for the long term mentally ill, ensuring that they remain in contact with mental illness services and their needs met. It provides computerised reminders for case managers to review their patients. Written in Oracle, it is flexible, allowing changes and integration into future information systems. Further information can be obtained from Mrs Sue Reynolds, Monitoring System Officer, Bootham Park Hospital, York YO3 7BY. 